\title{
Exclusive breastfeeding practice in Ethiopia and its association with antenatal care and institutional delivery: a systematic review and meta-analysis
}

Animut Alebel $^{1^{*}}$, Cheru Tesma ${ }^{2}$, Belisty Temesgen ${ }^{3}$, Aster Ferede $^{2}$ and Getiye Dejenu Kibret ${ }^{2}$

\begin{abstract}
Background: Despite the World Health Organization recommendation of exclusive breastfeeding (EBF) for the first six months of life, the rate remains low both in developed and developing countries. In Ethiopia, findings regarding the prevalence of EBF have been highly variable. Antenatal care and institutional delivery are the most important factors contributing to the practice of EBF however; their effect has not been investigated in Ethiopia.

Methods: In this systematic review and meta-analysis, international databases were systematically searched. All observational studies reporting the prevalence of EBF and its association with antenatal care and institutional delivery in Ethiopia were considered. Two authors independently extracted all necessary data using a standardized data extraction format. A random effects meta-analysis model was computed to estimate the pooled prevalence of exclusive breastfeeding. Moreover, the association of antenatal care and institutional delivery with EBF was determined.

Results: After reviewing 619 studies, 32 studies fulfilled the inclusion criteria and were included in the meta-analysis. The pooled prevalence of EBF in Ethiopia was 59.3\% (95\% Confidence Interval [CI] 53.8, 64.8). The subgroup analysis indicated that the highest prevalence was observed in Afar region (65.6\%), followed by SNNP (63.8\%), and then by Oromia (61.8\%). Additionally, mothers who attended antenatal visits were 2.1 times more likely to practice EBF compared to their counterparts (Odds Ratio [OR] 2.1; $95 \% \mathrm{Cl} 1.5,2.8$ ). Moreover, mothers who gave birth at a health institution were 2.2 times more likely to practice EBF compared to mothers who gave birth at home $(\mathrm{OR} 2.2 ; 95 \% \mathrm{Cl} 1$. 3, 3.5).

Conclusions: Exclusive breastfeeding in Ethiopia was significantly lower than the global recommendations. There was evidence that mothers who attended antenatal visits and who gave birth at health institutions had better EBF practices. Based on our findings, we strongly recommended that the utilization of antenatal care and institutional delivery should be improved through health extension workers.
\end{abstract}

Keywords: Prevalence, Exclusive breastfeeding, Meta-analysis, Systematic review, Ethiopia

\footnotetext{
* Correspondence: animut.a23@gmail.com

1 Department of Nursing, College of Health Sciences, Debre Markos

University, Debre Markos, Ethiopia

Full list of author information is available at the end of the article
}

(c) The Author(s). 2018 Open Access This article is distributed under the terms of the Creative Commons Attribution 4.0 International License (http://creativecommons.org/licenses/by/4.0/), which permits unrestricted use, distribution, and reproduction in any medium, provided you give appropriate credit to the original author(s) and the source, provide a link to the Creative Commons license, and indicate if changes were made. The Creative Commons Public Domain Dedication waiver (http://creativecommons.org/publicdomain/zero/1.0/) applies to the data made available in this article, unless otherwise stated. 


\section{Background}

Breast milk is the natural first food for babies, which provides all the energy and nutrients that the infant needs for the first 6 months of life [1]. The World Health Organization (WHO) recommends that infants should be exclusively breastfed for the first 6 months, and for an additional 18 months or longer, to be breastfed along with complementary foods for the achievement of satisfactory growth and development [2, 3]. Exclusive breastfeeding (EBF) is defined as giving breast milk to the infant, without any additional food or drink, not even water in the first 6 months of life, with the exception of vitamins, mineral supplements or medicines [4].

Although the benefit of exclusive breastfeeding is widely advocated globally, only $35 \%$ the of infants worldwide were exclusively breastfed during their first 4 months of life [5, 6]. In Africa, Asia, Latin America, and Caribbean countries, evidences suggested that only 47$57 \%$ of infants less than 2 months, and $25-31 \%$ of infants 2-5 months were exclusively breastfed [7]. Even though, Sub-Saharan Africa has one of the highest prevalence of breastfeeding at 1 year worldwide; however, only $37 \%$ of infants aged less than 6 months are exclusively breastfed [8]. Non-exclusive breastfeeding has been significantly associated with increased infants and young child mortality. Accordingly, almost $96 \%$ of all infant deaths that means 1.24 million deaths occur during the first 6 months of life are attributed to non-exclusive breastfeeding, this figure is substantially higher in Asian and African countries. In addition, non-exclusive breastfeeding also contributes to $55 \%$ of diarrheal deaths and $53 \%$ of acute respiratory deaths for the first 6 months of life [9]. Partial or no breastfeeding is associated with a 2.23-fold higher risk of infant deaths resulting from all causes and 2.40 and 3.94 fold higher risk of deaths attributable to pneumonia and diarrhea, respectively as compared with exclusive breastfeeding [10]. In Ethiopia, suboptimal breastfeeding contributes to an estimated number of 70,000 infant deaths, which accounts $24 \%$ total infant death annually. These deaths could be prevented through nutritional interventions like exclusive breastfeeding [11].

Antenatal Care (ANC) is one of the fundamental strategies recommended to reduce the risk of maternal and neonatal mortality both in developing and developed countries [12-15]. It is an ideal entry point for healthcare professionals to provide numerous healthcare interventions to promote maternal and fetal wellbeing including exclusive breastfeeding [16]. During ANC visits, different nutritional and other health related educations from healthcare professionals are provided, which could have a great contribution to the practice of exclusive breastfeeding. In addition, information provided by healthcare professions concerning infant feeding and the nutritional values of breast milk will increase the knowledge of exclusive breastfeeding [16]. According to WHO, to provide an effective ANC service of at least four ANC visits are recommended particular to low-income countries [17]. Moreover, an institutional delivery encourages infants to receive skin to skin contact from their mothers, and this will increase the likelihood of timely initiation of breastfeeding, exclusive breastfeeding and prolonged duration of breastfeeding $[18,19]$. Furthermore, institutional delivery has a great role to promote breastfeeding through a strategy of the Baby-Friendly Hospital Initiative (BFHI). The BFHI is a key component of the World Health Organization/ United Nations Children's Fund Global Strategy for Infant and Young Child Feeding [20].

In Ethiopia, different studies have been conducted to determine the prevalence of EBF and associated factors. The findings of these fragmented studies documented that there was a great variability in the prevalence of EBF across the regions of the country. Regarding associated factors, these studies revealed that different maternal and health service related factors influenced EBF; maternal educational level [21-26], current marital status [27, 28], place of residence [21, 29, 30], employment [21, 25, 28, 30-37], economic status of mothers [30,31,37, 38], institutional delivery [21, 23, 25, 27, 37, 39-42], history of antenatal $[22,29,33,37,38,43-45]$ and postnatal care [22, 23, 25, $29,33,34,37,39,43]$, were some of the factors associated with EBF practice. From these factors, we selected the two factors (ANC and institutional delivery) to see their effect on the practice of exclusive breastfeeding. We sorted these factors because of the following reasons: firstly, these factors were the most important factors, which ultimately influencing EBF. Secondly, the effect of ANC and institutional delivery on EBF have reported controversial findings. Regarding these findings, in some studies, ANC was positively associated with EBF $[22,24,28,29,31,37$, 39, 40, 42, 45-48]. On the other hand, one Ethiopian study disclosed that ANC was negatively associated with EBF [49]. Regarding institutional delivery, in some studies it was positively associated with $\mathrm{EBF}[21,25,28,30,31,36$, $37,39,40,42,43,45,47,50,51]$. On the other hand, in two studies it was inversely associated with EBF [41, 44]. Therefore, the above-mentioned factors required this meta-analysis.

For better intervention, current and up-to-dated information regarding the prevalence of EBF and its association with ANC and institutional delivery is vital, especially in low and middle-income countries like Ethiopia. However, despite these small and fragmented studies there was no nationwide study, which determines the prevalence of EBF and its association with ANC and institutional delivery in Ethiopia. Hence, the main aim of this systematic review and 
meta-analysis was to estimate the pooled prevalence of EBF and its association with ANC and institutional delivery in the context of Ethiopia. The findings of this study will be an input to policy makers and program planners working in the area of breastfeeding.

\section{Methods}

\section{Searching strategies}

The current systematic review and meta-analysis was reported by using the Preferred Reporting Items for Systematic Reviews and Meta-Analysis (PRISMA) [52] guideline to determine the pooled prevalence of exclusive breastfeeding practice and its association with ANC and institutional delivery in the context of Ethiopia. The international databases, including PubMed, Google scholar, Science direct and Cochrane library were systematically searched. The search was conducted using the following keywords "prevalence", "Exclusive breastfeeding", "Antenatal care", "Institutional delivery", "Place of delivery", "Birth place", "Skill birth attendance", and "Ethiopia". The search terms were used separately and in combination using Boolean operators like "OR" or "AND". The search was conducted from September 9 to October 10,
2017. All papers published until October 10, 2017 were included in this review.

\section{Eligibility criteria \\ Inclusion criteria}

Study area: Only studies conducted in Ethiopia.

Publication condition: Articles published in peer reviewed journals.

Study design: All observational study designs (Cross-sectional, case-control and cohort) reporting the prevalence of EBF or studies reporting the associations between ANC and institutional delivery with EBF were considered.

Outcome of interests: Studies reported data on the prevalence of EBF or the association between EBF and ANC or the association between EBF and institutional delivery were considered.

Language: Articles reported in the English language were considered.

\section{Exclusion criteria}

Articles, which were not fully accessed, after at least two email contact of the primary author were excluded. Exclusion of these articles is because of inability to assess the quality of articles in the absence of full text.

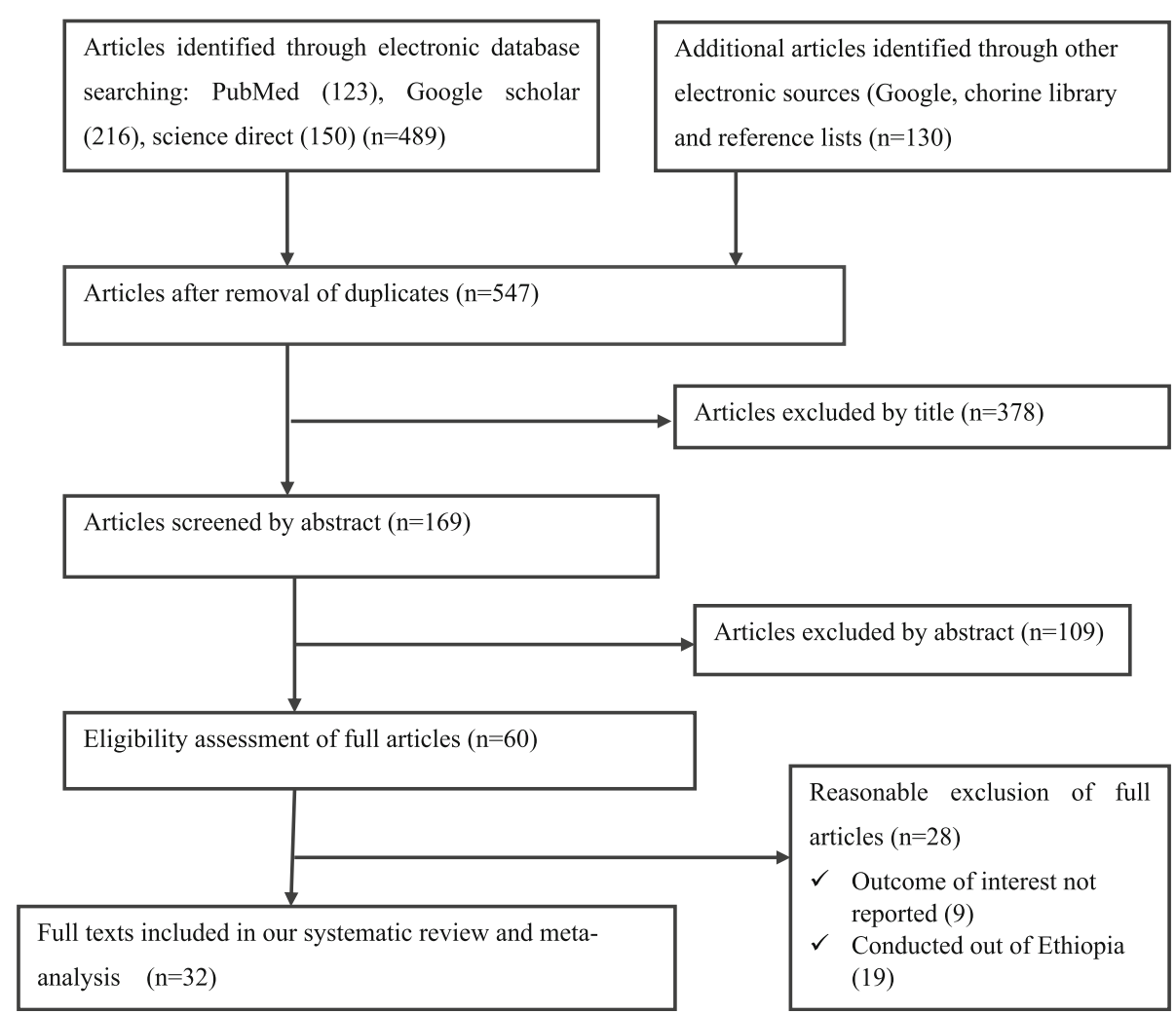

Fig. 1 Flow chart to describe the selection of studies for a systematic review and meta-analysis of the effects of ANC and institutional delivery on exclusive breastfeeding in Ethiopia, 2017 
Table 1 Descriptive summary of 32 studies included in the meta-analysis of the prevalence of exclusive breastfeeding in Ethiopia, 2017

\begin{tabular}{|c|c|c|c|c|c|c|c|}
\hline Primary author & $\begin{array}{l}\text { Publication } \\
\text { year }\end{array}$ & Study area & Study design & $\begin{array}{l}\text { Response rate } \\
(\%)\end{array}$ & $\begin{array}{l}\text { Sample } \\
\text { size }\end{array}$ & $\begin{array}{l}\text { Prevalence with } \\
95 \% \mathrm{Cl}\end{array}$ & $\begin{array}{l}\text { Quality } \\
\text { score }\end{array}$ \\
\hline Adugna et al. [28] & 2017 & Gozamen district & Cross-sectional & 97.8 & 541 & $60.9(56.7,65.0)$ & 8 \\
\hline Alemayehu et al. [27] & 2009 & EDHS 2005 based & EDHS 2005 based & $N R$ & 1142 & $49(46.1,51.9)$ & 6 \\
\hline $\begin{array}{l}\text { Alemu Earsido et al. } \\
\text { [26] }\end{array}$ & 2017 & Hossana town & Cross sectional & 98 & 720 & $73.8(70.6,77.1)$ & 5 \\
\hline $\begin{array}{l}\text { Arage and Gedamu } \\
\text { [42] }\end{array}$ & 2016 & Debre Tabor & Cross-sectional & 96.4 & 470 & $70.9(66.7,75.1)$ & 6 \\
\hline Asemahagn [37] & 2016 & Azezo district & Cross-sectional & 96 & 346 & $78.9(74.5,83.3)$ & 8 \\
\hline Asfaw et al. [30] & 2015 & $\begin{array}{l}\text { Debre Berhan } \\
\text { District }\end{array}$ & Cross-sectional & 100 & 634 & $68.6(65.0,72.2)$ & 7 \\
\hline Bekere et al. [36] & 2014 & West Oromia & Cross-sectional & 99.2 & 119 & $72(63.9,80.1)$ & 5 \\
\hline Berhe et al. [35] & 2013 & Mekelle town & Cross-sectional & 100 & 361 & $60.7(55.6,65.7)$ & 4 \\
\hline Biks et al. [45] & 2015 & Dabat district & $\begin{array}{l}\text { a nested case-control } \\
\text { study }\end{array}$ & $N R$ & 1769 & $30.7(28.6,32.8)$ & 8 \\
\hline Chekol et al. [47] & 2017 & Gondar town & Cross-sectional & $N R$ & 649 & $34.8(31.2,38.5)$ & 8 \\
\hline Genetu et al. [51] & 2017 & north Gondar zone & Cross-sectional & NR & 367 & $86.1(82.6,89.6)$ & 8 \\
\hline Gizaw et al. [50] & 2017 & Hadaleala district & Cross-sectional & 98.5 & 294 & $60.6(54.6,66.6)$ & 7 \\
\hline Hunegnaw et al. [25] & 2017 & Gozamin district & Cross-sectional & 94.4 & 506 & $74.1(70.1,78.0)$ & 8 \\
\hline Kitesa and Bekele [41] & 2017 & Marti district & Cross-sectional & 100 & 2222 & $44.3(42.3,46.4)$ & 6 \\
\hline Lenja et al. [24] & 2016 & Offa district & Cross-sectional & 98 & 403 & $78(74.0,82.1)$ & 8 \\
\hline Liben et al. [34] & 2016 & Dubti Town & Cross-sectional & 96.2 & 346 & $81.1(76.9,85.3)$ & 7 \\
\hline Mekuria and Edris [33] & 2015 & Debre Markos & Cross-sectional & 97.6 & 423 & $60.8(56.1,65.5)$ & 7 \\
\hline $\begin{array}{l}\text { Mukerem and Haidar } \\
\text { [59] }\end{array}$ & 2012 & Addis Ababa & Cross-sectional & 966 & 384 & $73(68.5,77.6)$ & 6 \\
\hline Reddy and Abuka [44] & 2016 & Dilla Zuria District & Cross-sectional & 98.8 & 352 & $57.6(52.4,62.8)$ & 3 \\
\hline Sefene et al. [23] & 2013 & Bahir Dar Town & Cross-sectional & 93.5 & 170 & $49.1(41.3,56.8)$ & 5 \\
\hline Seid et al. [40] & 2013 & Bahir Dar & Cross-sectional & 100 & 819 & $50.6(47.1,54)$ & 7 \\
\hline Seifu et al. [38] & 2014 & Jimma Town & Cross-sectional & 97.2 & 422 & $60.2(55.5,65.0)$ & 7 \\
\hline Setegn et al. [32] & 2012 & Goba district & Cross-sectional & 91 & 668 & $71.4(67.8,75.0)$ & 8 \\
\hline Shewayenesh [84] & 2007 & Yeka sub-city & Cross-sectional & 100 & 796 & $34(30.8,37.3)$ & 4 \\
\hline Shifraw et al. [43] & 2015 & Addis Ababa & Cross-sectional & 98 & 660 & $29.3(25.8,32.8)$ & 7 \\
\hline $\begin{array}{l}\text { Sonko and Worku } \\
\text { [22] }\end{array}$ & 2015 & $\begin{array}{l}\text { Halaba special } \\
\text { woreda }\end{array}$ & Cross-sectional & 99.5 & 422 & $70.5(66.1,74.8)$ & 8 \\
\hline Sorato [46] & 2017 & Chencha district & Cross-sectional & 92 & 248 & $40.7(54.5,66.4)$ & 6 \\
\hline Tariku et al. [48] & 2017 & Dabat District & $\begin{array}{l}\text { Demographic } \\
\text { Surveillance }\end{array}$ & NR & 5227 & $54.5(53.2,55.90$ & 8 \\
\hline Teka et al. [39] & 2015 & Enderta woreda & Cross-sectional & 98 & 541 & $70.2(66.3,74.1)$ & 7 \\
\hline Tewabe et al. [31] & 2017 & Motta town & Cross-sectional & 95.7 & 423 & $50.1(45.3,55.0)$ & 7 \\
\hline Tsegaye [21] & 2015 & Aysaita wereda & Cross-sectional & 98 & 631 & $55(51.1,58.9)$ & 6 \\
\hline Woldie et al. [29] & 2014 & Mecha district & Cross-sectional & 100 & 819 & $47.1(43.7,50.6)$ & 7 \\
\hline
\end{tabular}

\section{Outcome measurement}

This systematic review has three main outcomes. Exclusive breastfeeding practice, as the primary outcome variable of this study, is defined as giving breast milk to the infant, without any additional food or drink, not even water in the first 6 months of life, with the exception of vitamins, mineral supplements or medicines [4]. The prevalence was calculated from each primary study by dividing the number of women breastfeeding exclusively to the total number of women who had ever breastfed multiplied by 100 . The second outcome was to examine the association between ANC and exclusive 
breastfeeding. In this study, healthcare professionals considered antenatal care as if a mother received at least four antenatal care visits and more during her pregnancy period. The third outcome of this study was to determine the association between institutional delivery and exclusive breastfeeding. Institutional delivery was defined as giving birth at the health facility. For the second and the third outcomes, we calculated the log odds ratio based on the primary studies that examined the relationship between ANC, institutional delivery with exclusive breastfeeding.

\section{Data extraction}

Data were extracted using a standardized data extraction format, which was adopted from the JBI data extraction format. Two authors (AA and CT) independently extracted all necessary data using the format. Any disagreements at the time of data abstraction were resolved through discussion and consensus. The data extraction format included primary author, publication year, study area, study design, response rate, sample size, prevalence with $95 \% \mathrm{CI}$ and the quality score of each study.

\section{Quality assessment}

The Newcastle-Ottawa Scale for cross-sectional studies quality assessment tool was adapted and used to assess
Table 2 Related factors with heterogeneity of exclusive breastfeeding prevalence in the current meta-analysis (based on univariate meta-regression)

\begin{tabular}{lll}
\hline Variables & Coefficient & $p$-value \\
\hline Publication year & 1.01 & 0.76 \\
Sample size & 0.0007 & 0.84 \\
\hline
\end{tabular}

the quality of each study [53]. The tool has three major sections. The first section graded from five stars focuses on the methodological quality of each study. The second section of the tool deals with the comparability of the study. The last section deals with the outcomes and statistical analysis of each original study. Two authors independently assessed the quality of each original study using the tool. Disagreements between the two authors were resolved by taking the mean score of the two authors. Finally, research with a scale of $\geq 6$ out of 10 were considered as high quality.

\section{Statistical analysis}

Data were extracted in Microsoft Excel format, then analysis was done using STATA version 13 statistical software. The standard error for each original study was calculated using the binomial distribution formula. Heterogeneity among reported prevalence was assessed by

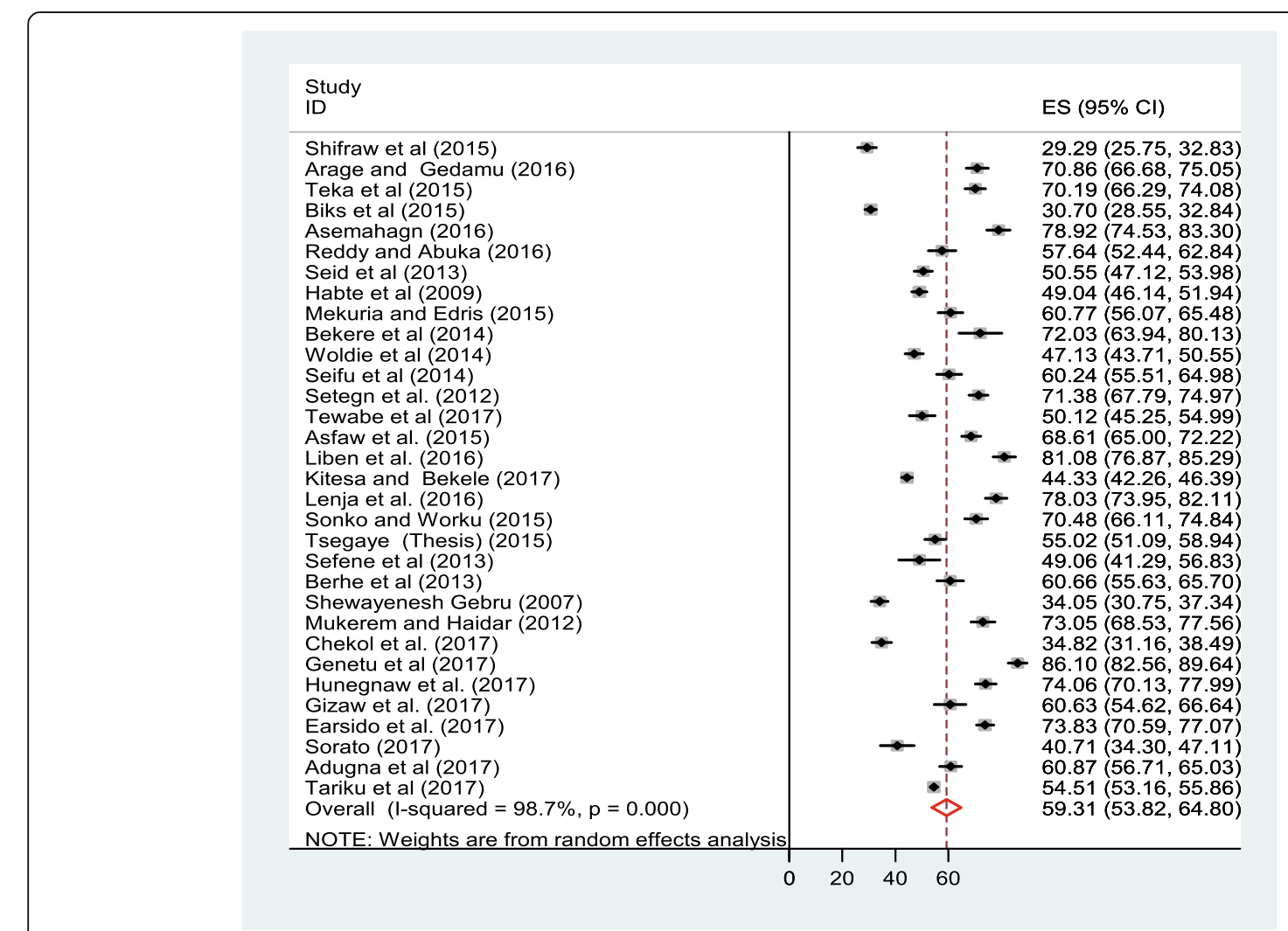

Fig. 2 Forest plot of the pooled prevalence of exclusive breastfeeding in Ethiopia 
Table 3 The subgroup prevalence of exclusive breastfeeding in Ethiopia, $2017(n=32)$

\begin{tabular}{lllll}
\hline Variables & Characteristics & Included studies & Sample size & Prevalence (95\% Cl) \\
\hline By regions & Addis Ababa & 3 & 1802 & $45.4(21.1,69.7)$ \\
& Amhara & 13 & 12,520 & $58.2(49.0,67.3)$ \\
& Oromia & 4 & 3358 & $61.8(46.1,77.6)$ \\
& Afar & 3 & 1,205 & $65.6(48.5,82.7)$ \\
& SNNP & 6 & 2,625 & $63.8(54.6,73.0)$ \\
By sample size & Others & 3 & 2033 & $59.9(46.3,73.5)$ \\
& $\geq 600$ & 13 & 16,641 & $49.5(42.1,56.8)$ \\
Overall & $<600$ & 19 & 6,902 & $66.2(61.2,71.3)$ \\
\hline
\end{tabular}

computing $p$-values for Cochrane Q-statistics and $I^{2}$ test [54]. As the test statistic showed there was a significant heterogeneity among the included studies $\left(I^{2}=98.7 \%, p<0.001\right)$ as a result a random effects meta-analysis model was used to estimate the Der Simonian and Laird's pooled effect. To minimize the random variations between the point estimates of the primary study subgroup, analysis was done based on study settings (i.e., the area where studies were conducted) and sample size. In addition, to identify the possible sources of heterogeneity univariate meta-regression was conducted by considering the sample size and year of publication as covariates but none of them were found to be statistically significant. Furthermore, Egger's and Begg's tests at 5\% significant level were not significant for publication bias [55]. Point prevalence as well as $95 \%$ confidence intervals were presented in the forest plot format. In this plot, the size of each box indicated the weight of the study, while each crossed line refers to 95\% confidence interval. For the second and third outcomes, log odds ratios were used to examine the association between ANC and institutional delivery with EBF.

\section{Results}

As shown in Fig. 1, in the first step of our search, 619 studies were identified regarding EBF in Ethiopia through PubMed, Google Scholar, Science Direct and others. Of which, 72 studies were excluded due to duplicates. From the remaining 547 studies, 378 articles were excluded after reviewing of their titles based on assessment as non-relevance to this review. The remaining 169 studies were screened by abstracts yielding an additional 109 being excluded. Moreover, 60 full text articles were accessed and assessed for eligibility based on the preset inclusion criteria. Of these, 28 articles were excluded due to the inclusion criteria. Among these, nine

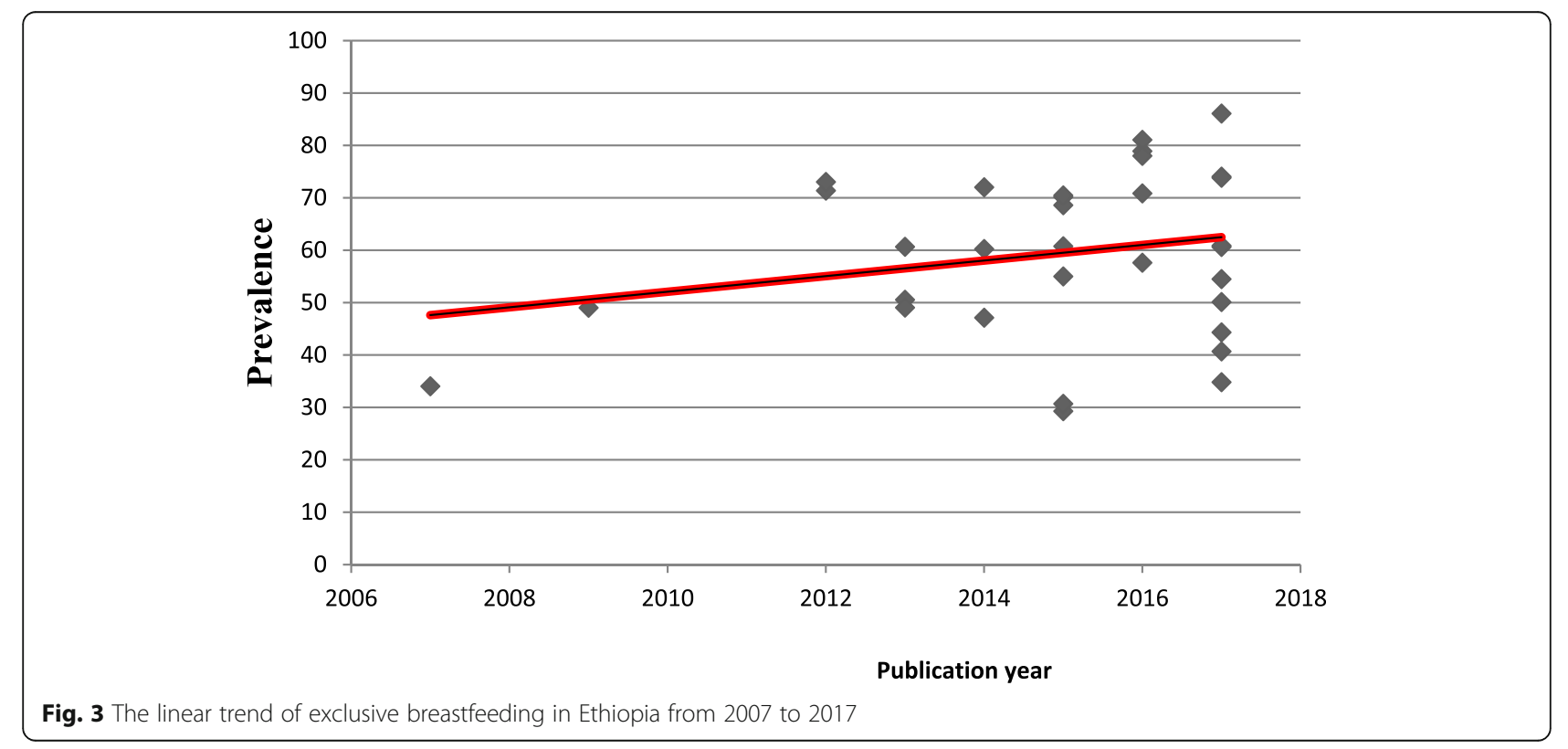


ID

OR $(95 \% \mathrm{Cl})$

Arage and Gedamu (2016)

Biks et al (2015)

Asemahagn (2016)

Reddy and Abuka (2016)

Seid et al (2013)

Bekere et al (2014)

Woldie et al (2014)

Tewabe et al. (2015)

Lenja et al. (2016)

Sonko and Worku (2015)

Shewayenesh Gebru (2007)

Teka et al. (2015)

Setegn et al (2012)

Chekol et al (2017)

Kasahun et al. (2017)

Hunegnaw et al (2017)

Sorato (2017)

Adugna et al (2017)

Tariku et al (2017)

Overall (l-squared $=88.6 \%, p=0.000$ )

NOTE: Weights are from random effects analysis

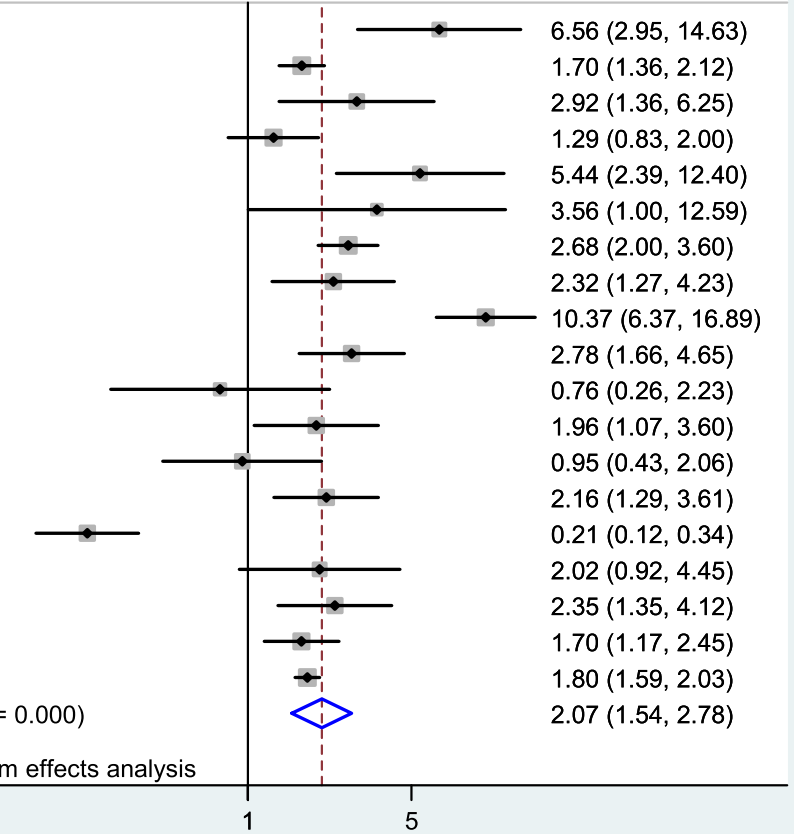

Fig. 4 The pooled odds ratio of the association between ANC and exclusive breastfeeding in Ethiopia

Study

ID

Shifraw et al. (2015)

Arage and Gedamu (2016)

Biks et al. (2015)

Asemahagn (2016)

Reddy and Abuka (2016)

Seid et al (2013)

Bekere et al (2014)

Tewabe et al (2017)

Asfaw et al. (2015)

Kitesa and Bekele (2017)

Sonko and Worku (2015)

Medhin Tsegaye (2015)

Shewayenesh Gebru (2007)

Teka et al. (2015)

Setegn et al (2012)

Chekol et al. (2017)

Genetu et al (2017)

Hunegnaw et al (2017)

Gizaw et al (2017)

Adugna et al (2017)

Overall ( $($-squared $=95.0 \%, p=0.000$ )

NOTE: Weights are from random effects analysis
OR $(95 \% \mathrm{Cl})$

$2.49(1.20,5.17)$

$4.38(2.67,7.16)$

$1.46(1.18,1.81)$

$2.45(1.36,4.41)$

$0.40(0.23,0.71)$

$4.02(2.30,7.02)$

$5.57(1.93,16.07)$

$3.29(1.84,5.89)$

$1.87(1.20,2.89)$

$0.21(0.17,0.28)$

$1.33(0.78,2.27)$

$4.36(3.07,6.20)$

$0.72(0.26,1.98)$

$2.18(1.43,3.32)$

$1.21(0.68,2.16)$

$2.67(1.40,5.09)$

$6.93(1.93,24.90)$

$3.87(2.14,6.98)$

$3.67(1.08,12.52)$

$5.52(3.50,8.70)$

$2.15(1.32,3.51)$

Fig. 5 The pooled odds ratio of the association between institutional delivery and exclusive breastfeeding in Ethiopia 
of the studies were excluded because they didn't report our outcome of interests $[49,56-62]$. The remaining 19 articles were excluded due to study settings; four of the studies were from Ghana [63-66], three of the studies were from Tanzania [67-69], one from Bangladesh [70], two from Cameroon [71, 72], two from India [73, 74], three from Kenya [75-77] one from Nigeria [78], two from Malaysia [79, 80], two from Congo [81, 82], and one from Nepal [83]. Finally, 32 studies fulfilled the inclusion criteria and included in the systematic review and meta-analysis.

\section{Description of the included studies}

As shown in Table 1, these 32 studies were published between 2007 to 2017. In the current meta-analysis, 23,543 breastfeeding women were included to estimate the pooled prevalence of exclusive breastfeeding. Regarding study design, most 29 (71.8\%) of the studies are cross-sectional study design. The sample size of the studies ranging from 119 to 5, 227. The lowest prevalence $(29.3 \%)$ of EBF was observed in a study conducted in Addis Ababa, Ethiopia [43] whereas the highest prevalence (86.1\%) was observed in a study conducted in north Gondar zone, northwest Ethiopia [51]. In this meta-analysis, from nine regions of the country seven regions were represented. Thirteen of the studies were from Amhara [23, 25, 29-31, 33, 37, $40,42,45,47,48,51]$, three from Addis Ababa [43, $59,84]$, three from Afar [21, 34, 50], four from Oromia [32, 36, 38, 41], six from SNNP [22, 24, 26, 28, $44,46]$, two from Tigray $[35,39]$. However, there were no studies reported from Benishangul Gumiz and Gagmbela regions. Concerning the quality score, the score ranged from lowest 3 to highest 8 . In related to response rate, almost all studies had a good response rate. The possible reason for this high response rate could be due to most of the studies used interviewers administered questionnaire to collect the data (Table 1).

\section{Meta-analysis}

The result of 32 included studies indicated that the pooled prevalence of EBF in Ethiopia was 59.3\% (95\% CI: $53.8,64.8 \%$ ) (Fig. 2). In this meta-analysis, Genetu et al. (86.1\%) reported the highest prevalence of EBF, whereas Shifraw et al. (29.3\%) reported the lowest prevalence of exclusive breastfeeding. The result of univariate meta-regression models was presented in the table below (Table 2). Publication bias was assessed using Begg's and Egger's tests, showing no statistical significant for estimating the prevalence of $\mathrm{EBF}(p=0.5)$ and $(p=0.2)$ respectively.

\section{Subgroup analysis}

In addition, in this meta-analysis, we performed subgroup analysis based on the regions where the studies were conducted and sample size of the studies. Accordingly, the highest prevalence was reported in Afar region with a prevalence of $65.6 \%$ (95\% CI: 48.5, 82.7\%) followed by SNNP, 63.8\% (95\% CI: 54.6, 73.0\%) and Oromia, $61.8 \%$ (95\% CI: 46.1, 77.6\%). With regard to sample size, the prevalence of EBF was higher in studies having a sample size <600, 66.2\% (95\% CI: $61.2,71.3 \%$ ) compared to those having a sample size $\geq 600,49.0 \%$ (95\% CI: 40.5, 57.6\%) (Table 3).

\section{The linear trend of exclusive breastfeeding in Ethiopia}

In this study, we also describe the linear trend of exclusive breastfeeding in Ethiopia from 2007 to 2017. We found that the general linear trend of exclusive breastfeeding was increased in each successive year (Fig. 3).

\section{Association between ANC and exclusive breastfeeding}

In this meta-analysis, we examined the association between ANC and EBF practice by using nineteen available studies [22, 24, 25, 28, 29, 31, 32, 36, 37, 39, 40, 42, 44$49,84]$. The findings from these nineteen studies revealed that the practice of EBF was significantly associated with antenatal care. Accordingly, the likelihood of EBF practice was 2.1 times higher among mothers' who had ANC visits as compared to their counterparts (OR: 2.1, 95 \%CI: 1.5, 2.8) (Fig. 4). High heterogeneity $\left(I^{2}=\right.$ $88.6 \%$ and $p$ - value $<0.001$ ) was observed across the included studies; hence, a random effect meta-analysis model was used to examine the association between ANC and EBF. For this analysis, we also assessed publication bias using Begg's and Egger's tests, the result of the test statistics indicated that there was no possible presence of statistically significant publication bias $(p=$ 0.4 and $(p=0.6)$ respectively.

\section{Association between institutional delivery and exclusive breastfeeding}

The third outcome of this research was to determine the association between institutional delivery and exclusive breastfeeding. Twenty studies, which examined the association between institutional delivery and EBF were considered to determine the association between EBF practice and institutional delivery $[21,22,25,28,30-32$, $36,37,39-45,47,50,51,84]$. In this study, the pooled odds ratio indicated that institutional delivery was positively associated with EBF (OR: 2.2, 95\% CI: 1.3, 3.5) (Fig. 5). In this meta-analysis, extreme heterogeneity $\left(I^{2}\right.$ $=95.0 \%$ and $p$ - value $<0.001)$ was observed across the studies hence, a random effect meta-analysis model was employed to estimate the pooled effect. Moreover, to detect the presence of publication bias, we did Begg's and 
Egger's tests. However, none of the tests were revealed significant publication bias with $p$ - value of 0.8 and 0.08 respectively.

\section{Discussion}

We conducted this systematic review and meta-analysis to estimate the pooled prevalence of EBF practice in Ethiopia and its association with ANC and institutional delivery. In Ethiopia, conducting this type of study will be paramount as input for program planners and policy makers working in the area of breastfeeding. The result of 32 included studies noted that the pooled prevalence of EBF in Ethiopia was 59.3\% (95\% CI: 53.8, 64.8\%). The overall prevalence indicated in this meta-analysis is higher than a meta-analysis conducted in Iran (49.1\%) [85]. In addition, this finding is higher than the national prevalence reported from other Sub-Saharan African countries included: Cameroon (28.2\%), Nigeria (17.4\%), Benin (43.1\%), Burkina Faso (50.1\%), and Ghana (52\%), [86]. On the other hand, our finding is slightly lower than the national prevalence of Malawi (61.2\%), Kenya (61.4\%), and Peru (68.4\%) [86]. The possible explanations for the above variations could be due to methodological differences (i.e., data analysis and sampling of study participants), variation in infants and maternal sociodemographic characteristics, economical, and health service utilization. Moreover, the higher prevalence of EBF in this meta-analysis could be attributed to the implementation of different strategies by the Ethiopian Government including the Health Extension Program [87].

In this study, we also performed sub-group analysis based on the study areas (i.e. Regions of the country) where the studies were conducted. The findings of the subgroup analysis indicated that extreme variability was observed in the prevalence of EBF across the regions of the country. The highest (65.6\%) prevalence of EBF was reported from the Afar region, whereas the lowest (45.4\%) prevalence of EBF was reported from Addis Ababa. The possible explanation for this variation could be due to the cultural variation across the regions of the country. In studies conducted in the Afar region, pastoralist communities were involved [88]. Therefore, the higher prevalence of EBF in Afar region could be due to the norm and culture to breastfeed the babies in the pastoralist communities [21]. Another possible explanation might be the difference in the implementation of health extension program [50]. Moreover, the high prevalence of EBF in Afar region could be also attributed to most of the women spent their time at home. Evidences suggested that mothers working at home is a major enhancing factors of exclusive breastfeeding $[89,90]$.

In this meta-analysis, we tried to describe the linear trend of exclusive breastfeeding in Ethiopia for the past ten years. From the result, we observed that the practice of exclusive breastfeeding practice was slightly increased from $34 \%$ in 2007 to $86.1 \%$ in 2017. The possible justification for the increased in the practice of EBF could be due to the fact that, the Ethiopian government has developed and implemented different infants and young child feeding guidelines and giving appropriate emphasis to key messages on exclusive breastfeeding practice since 2004 [91]. Additionally, different interventions are also launched as breastfeeding promotions have been given at health institutions and at the community level by community health extension workers and other healthcare providers [50]. Health information dissemination using different means, the preparation of training manuals and guidelines are some of the intervention strategies launched to enhance exclusive breastfeeding [28]. These factors could have a great contribution for the successive increment of exclusive breastfeeding through each year.

The current meta-analysis was also examined the association between ANC and EBF in Ethiopia context. Accordingly, antenatal care was significantly associated with exclusive breastfeeding. Mothers who had ANC visits were almost 2.1 times more likely to practice exclusive breastfeeding as compared to mothers who hadn't received antenatal care. This finding is consistent with the studies conducted in Rawalpindi [92] and Singapore [93]. This could be due to the fact that mothers who had ANC visit may receive different nutritional and other health related educations from health professionals during their follow up time these might have a great impact on exclusive breastfeeding [16]. Another conceivable explanation could be the increased knowledge and attitudinal changes due to the information provided by the healthcare professional about infants feeding and the nutritional values of breast milk.

Mothers who gave birth at a health institution were almost 2.2 times more likely to practice exclusive breastfeeding as compared to those who gave birth at home. This finding is in agreement with studies conducted in Ghana [94], India [73], Tanzania [95]. This might be because mothers who gave birth at health institution have a good opportunity to receive postnatal counseling regarding the importance of EBF, good position and attachment of breastfeeding from healthcare professionals. Supportive findings indicated that postnatal counseling regarding EBF have a great contribution to practice exclusive breastfeeding [23]. On the other hand, our finding contradicts with a study reported from Canada [96]. This study indicated that mothers who gave birth at home were more likely to practice EBF as compared to their counterparts. This controversy finding could be explained by socioeconomic and cultural variation across the study participants. 


\section{Limitations of the study}

Like other meta-analysis, this meta-analysis has several limitations. The first limitation of this study was only English articles or reports were considered to conduct this nationally based review. In addition, the majority of the studies included in this review were cross-sectional in nature as a result; the outcome variable might be affected by other confounding variables. Moreover, most of the studies included in this review had a small sample size. Therefore, this factor could affect the estimated reports. Furthermore, this meta-analysis represented only studies reported from seven regions of the country. Therefore, the regions may be under-represented due to the limited number of studies included.

\section{Conclusions}

The overall prevalence of EBF practice in Ethiopia was significantly low as compared to the global recommendation level of breastfeeding. Mothers who received ANC and an institutional delivery were significantly associated with the better EBF practice. Therefore, based on our findings, we strongly recommended that healthcare workers (midwives and obstetricians) should give a special emphasis to encourage mothers to attend antenatal and postnatal care to improve EBF practice as an opportunity to teach mothers about the importance of exclusive breastfeeding. In addition, improving utilization of antenatal care and institutional delivery through health extension workers are essential interventions to increase exclusive breastfeeding practice. Moreover, besides the institutional level, health extension workers shall give infant and young children feeding advice/counseling at the community.

\section{Abbreviations}

ANC: Antenatal Care; DHS: Demographic and Health Survey; EBF: Exclusive Breastfeeding; EDHS: Ethiopian Demographic and Health Survey; HSDP: Health Sector Development Plan; OR: Odds Ratio; WHO: World Health Organization

Availability of data and materials

Data will be available upon request of the corresponding author.

\section{Authors' contributions}

AA: Conception of research protocol, study design, literature review, data extraction, data analysis, interpretation and drafting the manuscript. CT, BT, AF and GDK: data extraction, quality assessment, data analysis and reviewing the manuscript. All authors have read and approved the manuscript.

\section{Ethics approval and consent to participate}

Not applicable.

\section{Consent for publication}

Not applicable.

\section{Competing interests}

The authors declare that they have no competing interests.

\section{Publisher's Note}

Springer Nature remains neutral with regard to jurisdictional claims in published maps and institutional affiliations.

\section{Author details}

${ }^{1}$ Department of Nursing, College of Health Sciences, Debre Markos University, Debre Markos, Ethiopia. ²Department of Public Health, College of Health Sciences, Debre Markos University, Debre Markos, Ethiopia. ${ }^{3}$ Debre Markos Referral Hospital, Debre Markos, Ethiopia.

Received: 24 November 2017 Accepted: 5 July 2018

Published online: 16 July 2018

\section{References}

1. World Health Organization: Exclusive breastfeeding available at http://www. who.int/nutrition/topics/exclusive_breastfeeding/en/.

2. World Health Organization: Complementary feeding: report of the global consultation, and summary of guiding principles for complementary feeding of the breastfed child. 2003.

3. World Health Organization and United Nations Children's Fund. Global strategy for infant and young child feeding: World Health Organization; 2003.

4. Rajeshwari K, Bang A, Chaturvedi P, Kumar V, Yadav B, Bharadva K, et al. Infant and young child feeding guidelines: 2010. Indian Pediatr. 2010;47(12): 995-1004.

5. World Health Organization and United Nations Children's Fund: Global strategy for infant and young child feeding. World Health Organization; 2003. Available from http://apps.who.int/iris/bitstream/handle/10665/42590/ 9241562218.pdf? sequence $=1$.

6. Du Plessis D. Breastfeeding: mothers and health practitioners in the context of private medical care in Gauteng. Health SA Gesondheid (Online). 2009; 14(1):39-48.

7. Lamberti LM, Fischer Walker CL, Noiman A, Victora C, Black RE. Breastfeeding and the risk for diarrhea morbidity and mortality. BMC Public Health. 2011;11(Suppl 3):S15.

8. Victora CG, Bahl R, Barros AJ, França GV, Horton S, Krasevec J. Breastfeeding in the 21st century: epidemiology, mechanisms, and lifelong effect. Lancet. 2016:387(10017):475-90

9. USAID: Program description, overall MCH and health sector situation. In. Ethiopia; 2008.

10. Arifeen S, Black RE, Antelman G, Baqui A, Caulfield L, Becker S. Exclusive breastfeeding reduces acute respiratory infection and diarrhea deaths among infants in Dhaka slums. Pediatrics. 2001;108(4):e67.

11. Ministry of Health: National newborn and child survival strategy document brief summary 2015/16-2019/20. 2015. Available from https://www.unicef. org/ethiopia/Child_Survival_Strategy.pdf.

12. Wehby GL, Murray JC, Castilla EE, Lopez-Camelo JS, Ohsfeldt RL. Prenatal care effectiveness and utilization in Brazil. Health Policy Plan. 2009;24(3):175-88.

13. Singh A, Pallikadavath S, Ram F, Alagarajan M. Do antenatal care interventions improve neonatal survival in India? Health Policy Plan. 2013; 29(7):842-8.

14. Lambon-Quayefio MP, Owoo NS. Examining the influence of antenatal care visits and skilled delivery on neonatal deaths in Ghana. Applied Health Economics and Health Policy. 2014;12(5):511-22.

15. Garrido GG. The impact of adequate prenatal care in a developing country: testing the WHO recommendations. Population Working Papers. 2017;

16. World Health Organization: Antenatal Care World Health Organization available at http://www.who.int/pmnch/media/publications/aonsectionlll_2.pdf.

17. Lawn J, Kerber K: Opportunities for Africas newborns: practical data policy and programmatic support for newborn care in Africa 2006.

18. Bramson L, Lee JW, Moore E, Montgomery S, Neish C, Bahjri K, et al. Effect of early skin-to-skin mother--infant contact during the first 3 hours following birth on exclusive breastfeeding during the maternity hospital stay. J Hum Lact. 2010;26(2):130-7.

19. Bhutta ZA, Das JK, Rizvi A, Gaffey MF, Walker N, Horton S, et al. Evidence-based interventions for improvement of maternal and child nutrition: what can be done and at what cost? Lancet. 2013;382(9890): 452-77.

20. Perez-Escamilla R, Martinez JL, Segura-Perez S. Impact of the baby-friendly hospital initiative on breastfeeding and child health outcomes: a systematic review. Matern Child Nutr. 2016;12(3):402-17. 
21. Tsegaye M: Assessment of the prevalence and associated factors of exclusive breastfeeding practice in afar. A community based cross sectional survey, Aysaita wereda, afar, Ethiopia. Addis Ababa University; 2015.

22. Sonko A, Worku A. Prevalence and predictors of exclusive breastfeeding for the first six months of life among women in Halaba special woreda, southern nations, nationalities and peoples' region/SNNPR/, Ethiopia: a community based cross-sectional study. Archives Public Health. 2015;73:53.

23. Sefene A, Birhanu D, Awoke W, Taye T. Determinants of exclusive breastfeeding practice among mothers of children age less than 6 month in Bahir Dar city administration, Northwest Ethiopia; a community based cross-sectional survey. Sci J Clin Med. 2013;2(6):153-9.

24. Lenja A, Demissie T, Yohannes B, Yohannis M. Determinants of exclusive breastfeeding practice to infants aged less than six months in Offa district, southern Ethiopia: a cross-sectional study. Int Breastfeed J. 2016;11:32.

25. Hunegnaw MT, Gezie LD, Teferra AS. Exclusive breastfeeding and associated factors among mothers in Gozamin district, Northwest Ethiopia: a community based cross-sectional study. Int Breastfeed J. 2017;12:30.

26. Earsido A, Abebe $W$, Dereje N. Prevalence and determinants of exclusive breastfeeding practices among infants in Hossana town, southern Ethiopia: a community based cross-sectional study. Ec Gynaecol. 2017;4.3(2017):69-79.

27. Alemayehu T, Haidar J, Habte D. Determinants of exclusive breastfeeding practices in Ethiopia. Ethiop J Health Dev. 2009;23(1)

28. Adugna B, Tadele H, Reta F, Berhan Y. Determinants of exclusive breastfeeding in infants less than six months of age in Hawassa, an urban setting, Ethiopia. Int Breastfeeding J. 2017;12:45.

29. Woldie TG, Kassa AW, Edris M. Assessment of exclusive breast feeding practice and associated factors in Mecha District, North West Ethiopia. Sci J Public Health. 2014;2(4):330-6.

30. Asfaw MM, Argaw MD, Kefene ZK. Factors associated with exclusive breastfeeding practices in Debre Berhan District, Central Ethiopia: a cross sectional community based study. Int Breastfeed J. 2015;10:23.

31. Tewabe T, Mandesh A, Gualu T, Alem G, Mekuria G, Zeleke H. Exclusive breastfeeding practice and associated factors among mothers in Motta town, east Gojjam zone, Amhara regional state, Ethiopia, 2015: a crosssectional study. Int Breastfeed J. 2017;12:12.

32. Setegn T, Belachew T, Gerbaba M, Deribe K, Deribew A, Biadgilign S. Factors associated with exclusive breastfeeding practices among mothers in Goba district, south East Ethiopia: a cross-sectional study. Int Breastfeed J. 2012;7:17.

33. Mekuria G, Edris M. Exclusive breastfeeding and associated factors among mothers in Debre Markos, Northwest Ethiopia: a cross-sectional study. Int Breastfeed J. 2015:10:1.

34. Liben ML, Gemechu YB, Adugnew M, Asrade A, Adamie B, Gebremedin E, et al. Factors associated with exclusive breastfeeding practices among mothers in dubti town, afar regional state, Northeast Ethiopia: a community based cross-sectional study. Int Breastfeed J. 2016;11:4

35. Berhe $H$, Mekonnen B, Bayray A, Berhe $H$. Determinants of breast feeding practices among mothers attending public health facilities, Mekelle, northern Ethiopia; a cross sectional study. Int J Pharm Sci Res. 2013;4(2):650.

36. Bekere A, Garoma W, Beyene F. Exclusive breastfeeding practices of HIV positive mothers and its determinants in selected health institution of West Oromia, Ethiopia. J Nutr Food Sci. 2014;4(6):1.

37. Asemahagn MA. Determinants of exclusive breastfeeding practices among mothers in azezo district, Northwest Ethiopia. Int Breastfeeding J. 2016:11:22

38. Seifu W, Assefa G, Egata G. Prevalence of exclusive breast feeding and its predictors among infants aged six months in Jimma town, Southwest Ethiopia, 2013. J Pediatr Neonatal Care. 2014;1(3):00017.

39. Teka B, Assefa H, Haileslassie K. Prevalence and determinant factors of exclusive breastfeeding practices among mothers in Enderta woreda, Tigray, North Ethiopia: a cross-sectional study. Int Breastfeed J. 2015;10:2.

40. Seid AM, Yesuf ME, Koye DN. Prevalence of exclusive breastfeeding practices and associated factors among mothers in Bahir Dar City, Northwest Ethiopia: a community based cross-sectional study. Int Breastfeed J. 2013;8:14

41. Kitesa B, Bekele H. Assessment of exclusive breast-feeding and associated factors among anti natal (ANC) and non-ANC mothers in upper Awash Basin of Ethiopia. Int J Clin Dev Anatomy. 2017;2(3):9-18.

42. Arage $\mathrm{G}, \mathrm{Gedamu} \mathrm{H}$. Exclusive breastfeeding practice and its associated factors among mothers of infants less than six months of age in Debre Tabor town, Northwest Ethiopia: a cross-sectional study. Advances Public Health. 2016;
43. Shifraw T, Worku A, Berhane Y. Factors associated exclusive breastfeeding practices of urban women in Addis Ababa public health centers, Ethiopia: a cross sectional study. Int Breastfeed J. 2015;10:22.

44. Reddy S, Abuka T. Determinants of exclusive breastfeeding practice among mothers of children under two years old in Dilla Zuria District, Gedeo zone, SNNPR, Ethiopia, 2014. J Pregnancy Child Health. 2016;3:1.

45. Biks GA, Tariku A, Tessema GA. Effects of antenatal care and institutional delivery on exclusive breastfeeding practice in Northwest Ethiopia: a nested case-control study. Int Breastfeed J. 2015;10:30.

46. Sorato MM. Levels and predictors of exclusive breast feeding among rural mothers with children age 0-12 months in rural Kebeles of Chencha District. Snnpr, Gamo Gofa Zone, Ethiopia. 2016;1:77-90.

47. Chekol DA, Biks GA, Gelaw YA, Melsew YA. Exclusive breastfeeding and mothers' employment status in Gondar town, Northwest Ethiopia: a comparative cross-sectional study. Int Breastfeed J. 2017:12:27.

48. Tariku A, Alemu K, Gizaw Z, Muchie KF, Derso T, Abebe SM, et al. Mothers' education and ANC visit improved exclusive breastfeeding in Dabat health and demographic surveillance system site, Northwest Ethiopia. PLoS One. 2017;12(6):e0179056.

49. Kasahun AW, Wako WG, Gebere MW, Neima GH. Predictors of exclusive breastfeeding duration among 6-12 month aged children in gurage zone, South Ethiopia: a survival analysis. Int Breastfeed J. 2017;12:20.

50. Gizaw Z, Woldu W, Bitew BD. Exclusive breastfeeding status of children aged between 6 and 24 months in the nomadic population of Hadaleala district, afar region, northeast Ethiopia. Int Breastfeed J. 2017; 12:38.

51. Genetu H, Yenit MK, Tariku A. Breastfeeding counseling and support are associated with continuous exclusive breastfeeding from one week to six months of age among HIV exposed infants in North Gondar zone, Ethiopia: a cross-sectional study. Int Breastfeed J. 2017;12:21.

52. Liberati A, Altman DG, Tetzlaff J, Mulrow C, Gøtzsche PC, loannidis JP, et al. The PRISMA statement for reporting systematic reviews and metaanalyses of studies that evaluate health care interventions: explanation and elaboration. PLoS Med. 2009;6(7):e1000100.

53. Newcastle-Ottawa Scale customized for cross-sectional studies In. available from https://static-content.springer.com/esm/.../12889_2012_5111_ MOESM3_ESM.doc.

54. Rücker G, Schwarzer G, Carpenter JR, Schumacher M. Undue reliance on I 2 in assessing heterogeneity may mislead. BMC Med Res Methodol. 2008;8:79.

55. Borenstein $M$, Hedges LV, Higgins J, Rothstein HR. A basic introduction to fixed-effect and random-effects models for meta-analysis. Res Synthesis Methods. 2010;1(2):97-111.

56. Yeneabat $T$, Belachew $T$, Haile M. Determinants of cessation of exclusive breastfeeding in Ankesha Guagusa Woreda, Awi zone, Northwest Ethiopia: a cross-sectional study. BMC Pregnancy Childbirth. 2014;14:262.

57. Taddele M, Abebe L, Fentahun N. Exclusive breastfeeding and maternal employment in Ethiopia: a comparative cross-sectional study. Int J Nutr Food Sci. 2014;3(6):497-503.

58. Sinshaw $Y$, Ketema $K$, Tesfa M. Exclusive breast feeding practice and associated factors among mothers in Debre Markos town and Gozamen district, east Gojjam zone, North West Ethiopia. J Food Nutr Sci. 2015; 3(5):174-9.

59. Mukerem M, Haidar J. Assessment of the prevalence and factors influencing adherence to exclusive breast feeding among HIV positive mothers in selected health institution of Addis Ababa, Ethiopia. Ethiopian J Health Dev. 2012;26(3):169-75.

60. Minas AG, Ganga-Limando M. Social-cognitive predictors of exclusive breastfeeding among primiparous mothers in Addis Ababa, Ethiopia. PloS One. 2016;11(10):e0164128.

61. Fenta EH, Yirgu R, Shikur B, Gebreyesus SH. A single 24 h recall overestimates exclusive breastfeeding practices among infants aged less than six months in rural Ethiopia. Int Breastfeed J. 2017;12:36.

62. Frehiwot $\mathrm{W}$, Jemal $\mathrm{H}$, Bilal $\mathrm{S}$ : Assessment of factors associated with exclusive breastfeeding practice employed and unemployed mother: a community based acomparative cross sectional study Woldiya, Ethiopia Addis Ababa University 2015.

63. Dun-Dery EJ, Laar AK. Exclusive breastfeeding among city-dwelling professional working mothers in Ghana. Int Breastfeed J. 2016;11:23.

64. Dun-Dery E: The practice of exclusive breastfeeding among professional working mothers in Wa central municipality, Ghana. University of Ghana; 2015. 
65. Boakye-Yiadom A, Yidana A, Sam NB, Kolog B, Abotsi A. Factors associated with exclusive breastfeeding practices among women in the west Mamprusi District in northern Ghana: a cross-sectional study. Public Health Research. 2016;6(3):91-8.

66. AK-A D, Bam V, Asante E, Lomotey AY, Yeboah S, Owusu HA. Challenges and predictors of exclusive breastfeeding among mothers attending the child welfare clinic at a regional hospital in Ghana: a descriptive crosssectional study. Int Breastfeed J. 2017;12:13.

67. Victor R, Baines SK, Agho KE, Dibley MJ. Determinants of breastfeeding indicators among children less than 24 months of age in Tanzania: a secondary analysis of the 2010 Tanzania demographic and health survey. BMJ Open. 2013;3(1):e001529.

68. Mgongo M, Mosha MV, Uriyo JG, Msuya SE, Stray-Pedersen B. Prevalence and predictors of exclusive breastfeeding among women in Kilimanjaro region, northern Tanzania: a population based cross-sectional study. Int Breastfeed J. 2013;8:12.

69. Maonga AR, Mahande MJ, Damian DJ, Msuya SE. Factors affecting exclusive breastfeeding among women in Muheza District Tanga northeastern Tanzania: a mixed method community based study. Matern Child Health J. 2016;20(1):77-87.

70. Joshi PC, Angdembe MR, Das SK, Ahmed S, Faruque ASG, Ahmed T. Prevalence of exclusive breastfeeding and associated factors among mothers in rural Bangladesh: a cross-sectional study. Int Breastfeed J. 2014;9:7.

71. Fombong FE, Olang B, Antai D, Osuorah CD, Poortvliet E, Yngve A. Maternal socio-demographic determinants of exclusive breastfeeding practice in Cameroon. Am J Food Nutr. 2016;4(4):83-92.

72. Chiabi A, Kamga B, Mah E, Bogne J, Nguefack S, Fokam P, et al. Breastfeeding practices in infants in the west region of Cameroon. Iranian J Public Health. 2011;40(2):11-7.

73. Sapna S, Ameya A, Rooma S, Aarti P, Rashid A, Narayan K. Prevalence of exclusive breastfeeding and its correlates in an urban slum in western India. Int J Sci Med Educ. 2009;3(2):14-8.

74. Radhakrishnan S, Balamuruga SS. Prevalence of exclusive breastfeeding practices among rural women in Tamil Nadu. Int J Health Allied Sci. 2012; 1(2):64.

75. Njeri Mututho Leah: Factors influencing exclusive breastfeeding among infants less than 6 months in kasarani informal settlement, Molo District, Kenya. Kenyatta University; 2012.

76. Lakati A, Binns C, Stevenson M. The effect of work status on exclusive breastfeeding in Nairobi. Asia Pacific J Public Health. 2002;14(2):85-90.

77. Ayisi R, Thuita F, Njeru E, Wakoli A. Factors associated with exclusive breastfeeding among infants aged 0-6 months in a peri-urban low income settlement of Kangemi, Nairobi. Global J Biol, Agricult Health Sci. 2014;3(4): 180-7.

78. Uchendu U, Ikefuna A, Emodi I. Factors associated with exclusive breastfeeding among mothers seen at the University of Nigeria Teaching Hospital. South African J Child Health. 2009;3(1):14-9.

79. Tan KL. Factors associated with exclusive breastfeeding among infants under six months of age in peninsular Malaysia. Int Breastfeed J. 2011;6:2.

80. Fatimah S, Saadiah H, Tahir A, Imam M, Faudzi YA. Breastfeeding in Malaysia: results of the third National Health and morbidity survey (NHMS III) 2006. Malays J Nutr. 2010;16(2)

81. Dhakal S, Lee TH, Nam EW. Exclusive breastfeeding practice and its association among mothers of under 5 children in Kwango District, DR Congo. Int J Environmental Res Public Health. 2017;14(5):455.

82. Babakazo P, Donnen P, Akilimali P, Ali NMM, Okitolonda E. Predictors of discontinuing exclusive breastfeeding before six months among mothers in Kinshasa: a prospective study. Int Breastfeed J. 2015;10:19.

83. Khanal V, Sauer K, Zhao Y. Exclusive breastfeeding practices in relation to social and health determinants: a comparison of the 2006 and 2011 Nepal demographic and health surveys. BMC Public Health. 2013;13:958.

84. Gebru S. Assesment of breastfeeding practice in Yeka sub-city Addis Ababa, Ethiopia. Addis Ababa University; 2007.

85. Ranjbaran M, Nakhaei MR, Chizary M, Shamsi M. Prevalence of exclusive breastfeeding in Iran: systematic review and meta-analysis. Int J Epidemiol Res. 2016;3(3):294-301.

86. World Health Organization: Exclusive breastfeeding under 6 months Data by country. Available at http://webcache.googleusercontent.com/search?q= cache:RXydFMrJ48cJ:apps.who.int/gho/dataview.main.NUT1730+\&cd=3\&hl= $\mathrm{om} \& \mathrm{ct}=\mathrm{clnk} \& \mathrm{gl}=\mathrm{et}$.
87. Federal Ministry of Health of Ethiopia: Health sector development program IV (2010/11-2014/15). 2010. Available at https://phe-ethiopia.org/admin/ uploads/attachment-721-HSDP\%20IV\%20Final\%20Draft\%20110ctoberr\% 202010.pdf.

88. Belachew $A B$, Kahsay AB, Abebe $Y G$. Individual and community-level factors associated with introduction of prelacteal feeding in Ethiopia. Archiv Public Health. 2016;74:6.

89. Murtagh L, Moulton AD. Working mothers, breastfeeding, and the law. Am J Public Health. 2011;101(2):217-23.

90. Dearden KA, Quan LN, Do M, Marsh DR, Pachón H, Schroeder DG, et al. Work outside the home is the primary barrier to exclusive breastfeeding in rural Viet Nam: insights from mothers who exclusively breastfed and worked. Food Nutr Bull. 2002;23(4_suppl2):99-106.

91. Federal Ministry of Health Family Health Department Ethiopia: National strategy for infant and young child feeding. 2004. Available at https:// extranet.who.int/nutrition/gina/sites/default/files/ETH\%202004\%20National \%20Strategy\%20for\%20Infant\%20and\%20Young\%20Child\%20Feeding.pdf.

92. Ahmad MO, Sughra U, Kalsoom U, Imran M, Hadi U. Effect of antenatal counselling on exclusive breastfeeding. J Ayub Med College Abbottabad. 2012;24(2):116-9.

93. Mattar CN, Chong Y-S, Chan Y-S, Chew A, Tan P, Chan Y-H, et al. Simple antenatal preparation to improve breastfeeding practice: a randomized controlled trial. Obstet Gynecol. 2007;109(1):73-80.

94. Aidam BA, Perez-Escamilla R, Lartey A, Aidam J. Factors associated with exclusive breastfeeding in Accra, Ghana. Eur J Clin Nutr. 2005;59(6):789-96.

95. Nkala TE, Msuya SE. Prevalence and predictors of exclusive breastfeeding among women in Kigoma region, western Tanzania: a community based cross-sectional study. Int Breastfeed J. 2011;6:17.

96. Chudasama RK, Amin CD, Parikh YN. Prevalence of exclusive breastfeeding and its determinants in first 6 months of life: a prospective study. Online J Health Allied Sci. 2009;8(1)

\section{Ready to submit your research? Choose BMC and benefit from:}

- fast, convenient online submission

- thorough peer review by experienced researchers in your field

- rapid publication on acceptance

- support for research data, including large and complex data types

- gold Open Access which fosters wider collaboration and increased citations

- maximum visibility for your research: over $100 \mathrm{M}$ website views per year

At BMC, research is always in progress.

Learn more biomedcentral.com/submissions 